First publ. in: Colloids and Surfaces A : Physicochemical and Engineering Aspects ; 270/271 (2005). pp. 340-344

\title{
Silver particles tailoring of shapes and sizes
}

\author{
J. Widoniak, S. Eiden-Assmann*, G. Maret \\ Fachbereich Physik, Universität Konstanz, 78457 Konstanz, Germany
}

\begin{abstract}
Dispersions of colloidal silver have been prepared by the reduction of silver nitrate, with different reductants in the presence of various stabilising agents. Aging these dispersions at room temperature for $2 \mathrm{~h}$ yielded particles with average sizes ranging from $1 \mathrm{~nm}$ up to $6 \mu \mathrm{m}$ and with various shapes like spheres, plates, needles or leafs. Reducing and stabilising agents were found to control the fina particle sizes and shapes. The diversity of morphologies of the silver particles were studied by using electron microscopy. Thermogravimetry, powder X-ray diffraction (XRD) and UV/VIS spectroscopy were carried out for further characterisation.
\end{abstract}

Keywords: Silver particles; Stabilising agent; Reducing agent; Control of size; Control of shape

\section{Introduction}

Recently, much effort has been devoted to the controlled synthesis of various particles on nanometer and micrometer scale. Colloidal noble metal particles are required in many field of science and technology. Usually their size, size distribution and shape need to be well define for applications in physical, chemical, biological or even medical areas. In particular, metal particles, like silver colloids, are very interesting for potential applications, such as quantum dots or in miniaturization of electronic devices, due to their unique optical and electrical properties. Since the discovery of surface-enhanced Raman spectroscopy (SERS) in the 1970s, silver nanoparticles have been used as substrates [1]. Large surface area and extraordinary surface activity make these small particles ideal catalysts and photo catalysts for many organic reactions [1].

Depending on synthesis techniques and the kind of stabilising and reducing agent, particles with various properties can be generated. Several publications described the synthesis of silver or other noble metal particles [1-5]. The most frequent preparation of silver nanoparticles is the reduction of silver salts by sodium borohydride or sodium citrate [1]. However, there are also some novel routes to obtain colloidal silver. Silvert et. al for instance specifie the synthesis of crystalline silver nanoparticles with sizes in the range from 15 to $36 \mathrm{~nm}$. They are obtained in a polyol synthesis, by reduction of silver nitrate in ethylene

\footnotetext{
* Corresponding author.
}

glycol, in the presence of polyvinylpyrrolidone (PVP) as stabilising agent [2]. Nakamoto and co-worker reported in 2003 the synthesis of silver nanoparticles with average diameter of $4.4 \mathrm{~nm}$ prepared via an amine adduct by the reaction of insoluble silver myristate with tertiary alkyl amine [4]. Van Blaaderen and co-workers describe the preparation of silver particles (up to $1200 \mathrm{~nm}$ in diameter) by reducing silver nitrate with ascorbic acid in aqueous solution in the presence of a polymeric steric stabiliser [3].

The addition of a stabilising agent is essential to prevent the agglomeration of colloidal particles in the dispersion. Non-ionic polymers build a coating on the particle surface and cause a steric stabilisation, while ionic polymers generate an additional electrostatic stabilisation of the colloids [6]. Some polymers and organic salts like PVP or vinyl sulfonate have a huge potential to control the growth of inorganic crystallites, like those of silver. This property is due to their strong interaction with inorganic surfaces. Recently molecules, which are able to control the particle growth and consequently their self-organisation became very important [5]. Xia and Sun described the shape-controlled synthesis of silver nanocubes via polyol method $[7,8]$. Cölfen and co-workers reported strong interactions between alkali earth ions and functional groups of block copolymers $[9,10]$. Depending on the type of polymeric the functionalisation pattern, it was possible to grow two different crystal modification of $\mathrm{CaCO}_{3}$, vaterite and calcite, under similar conditions. Additionally, they established that different shapes and sizes could be obtained by the variation of functional groups. Mann and co-worker describe similar works [11], they produced barium chromate 
Table 1

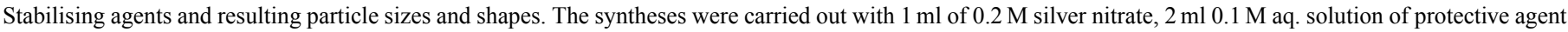
and $8 \mathrm{ml}$ Millipore water. Ascorbic acid (35 mg) was added as reductant

\begin{tabular}{|c|c|c|}
\hline Stabilising agent & Particle shape & Particle size \\
\hline- & $\begin{array}{l}\text { Rice balls consisting } \\
\text { of rod like particles }\end{array}$ & $2-4 \mu \mathrm{m}, 300-600 \mathrm{~nm}$ \\
\hline $\begin{array}{l}\text { Pluronic PE PEO-PPO-PEO-block } \\
\text { copolymer non-ionic surfactant }\end{array}$ & $\begin{array}{l}\text { Rice balls consisting } \\
\text { of rod like particles }\end{array}$ & $2-4 \mu \mathrm{m}, 300-600 \mathrm{~nm}$ \\
\hline $\begin{array}{l}\text { Plurafac LF non-ionic } \\
\text { surfactant }\end{array}$ & $\begin{array}{l}\text { Rice balls consisting } \\
\text { of rode like particles }\end{array}$ & $2-4 \mu \mathrm{m}, 300-600 \mathrm{~nm}$ \\
\hline $\begin{array}{l}\text { Gummi arabicum } \\
\text { polysaccharide }\end{array}$ & $\begin{array}{l}\text { Rice balls consisting } \\
\text { of rode like particles }\end{array}$ & $2-4 \mu \mathrm{m}, 300-600 \mathrm{~nm}$ \\
\hline $\begin{array}{c}\text { LutensitA-ES sodium alkylphenol } \\
\text { ether sulfate anionic surfactant }\end{array}$ & $\begin{array}{l}\text { Very thin and large } \\
\text { plates }\end{array}$ & $-20,000 \mu \mathrm{mm}$ \\
\hline $\begin{array}{l}\text { Tamol VS vinylsulfonate, } \\
\mathrm{Na} \text {, salt }\end{array}$ & $\begin{array}{l}\text { Crystallites } \\
\text { leafs }\end{array}$ & $5-6 \mu \mathrm{m}$ up to $20 \mu \mathrm{m}$ \\
\hline $\begin{array}{l}\text { Emulphor FAS } 30 \text { alkylphenolate-free } \\
\text { ether, } \mathrm{Na} \text {, salt }\end{array}$ & $\begin{array}{l}\text { Crystallites, leafs, hexagons, plates, } \\
\text { particles }\end{array}$ & $2-4 \mu \mathrm{m}$ up to $3 \mu \mathrm{m}$ \\
\hline $\begin{array}{l}\text { PVP, } \\
\text { polyvinylpyrrolidone }\end{array}$ & $\begin{array}{l}\text { Hexagons, } \\
\text { plates, particles }\end{array}$ & $1-3 \mu \mathrm{m} \mathrm{300-500} \mathrm{nm}$ \\
\hline
\end{tabular}

nanoparticles with three various shapes - cuboids, beads and long filament - in microemulsion droplets by variation of the reactant ratio. The cuboids can self-assemble in linear chains and rectangular superlattices.

Colloidal dispersions of silver particles with sizes from $1 \mathrm{~nm}$ to $6000 \mu \mathrm{m}$ have been synthesised in an aqueous solvent by the reduction of silver nitrate with ascorbic acid, iron ammonium citrate, sodium borohydride or hydroquinone. As stabilising agents we used various polymers; some of them are listed in the Table 1. Depending on the type of used reducing and stabilising agent, we were able to control the sizes and the shapes of the obtained silver particles.

\section{Experimental}

\subsection{Materials}

All reagents and solvents were used as received without further purification Silver nitrate, sodium borohydride and the alkali halide salts were purchased from Roth; ascorbic acid from Acros Organics; iron (III) ammonium citrate, hydroquinone, gummi arabicum (acacia, powder) and PVP K 30 (polyvinylpyrrolidone) from Aldrich; PVP K 25 from Fluka. Pluronic PE, Plurafac LF, Tamol VS, Emulphor FAS 30 and Lutensit A-ES were donated by BASF.

\subsection{Synthesis of silver particles}

The concentrations of the reactants and the solvent were varied to determine the ratios leading to narrow size distributions and uniformity in shapes of the silver particles. The concentration of silver nitrate in the reaction solution was varied between $0.01 \mathrm{M}$ and $0.10 \mathrm{M}$. An equimolar amount of the reductive agent was added. Additionally, the concentration of the reductive agent was varied between $0.01 \mathrm{M}$ and $0.10 \mathrm{M}$. The concentration of stabilising agent was also varied between $0.01 \mathrm{M}$ and $0.10 \mathrm{M}$. The optimum condition was found to be
$1.0 \mathrm{ml}$ of $0.20 \mathrm{M}$ aqueous silver nitrate solution, 0.02 mole of reductive agent, $2.0 \mathrm{ml}$ of $0.1 \mathrm{M}$ polymer solution, and $8.0 \mathrm{ml}$ Millipore water acting as solvent. In the firs step, Millipore water was mixed with the aqueous solution of the polymer, then the reductive agent was added. In the last step silver nitrate was added. The precipitation starts immediately and the reaction mixture was stirred for $2 \mathrm{~h}$ at room temperature. After ageing, the dispersions were centrifuged to obtain the silver particles. All syntheses were carried out under daylight.

\subsection{Characterisation of silver particles}

Scanning electron micrographs (SEM) of silver particles were obtained on a Philips scanning electron microscope (XL Series). Transmission electron micrographs were obtained on a Zeiss EM 900 microscope.

Water and polymer content of the silver particles was determined thermogravimetrically using a Netzsch-Thermoanalyser STA $429\left(\mathrm{O}_{2}\right.$ atmosphere, heating rate $\left.10 \mathrm{~K} / \mathrm{min}\right)$ combining thermogravimetry (TG), differential thermogravimetry (DTG), and differential thermal analysis (DTA).

Crystallinity and phase-purity of the products was monitored by powder X-ray diffraction (XRD) using a Guinier-Huber camera 600 with $\mathrm{Cu} \mathrm{K} \alpha_{1}$ radiation.

Extinction measurements (UV-vis) were carried out with a Varian Cary 50 spectrometer in the wavelength range between 200 and $1000 \mathrm{~nm}$.

The elemental composition was investigated by EDX and elemental analysis.

\section{Results and discussion}

Depending on the type of reducing and stabilising agent, the reduction of silver nitrate in water yielded dispersions of silver particles with various sizes and shapes. Powder XRD of the samples showed diversity in peak intensity and width (Fig. 1). The peak width corresponded to the size of the primary particles 

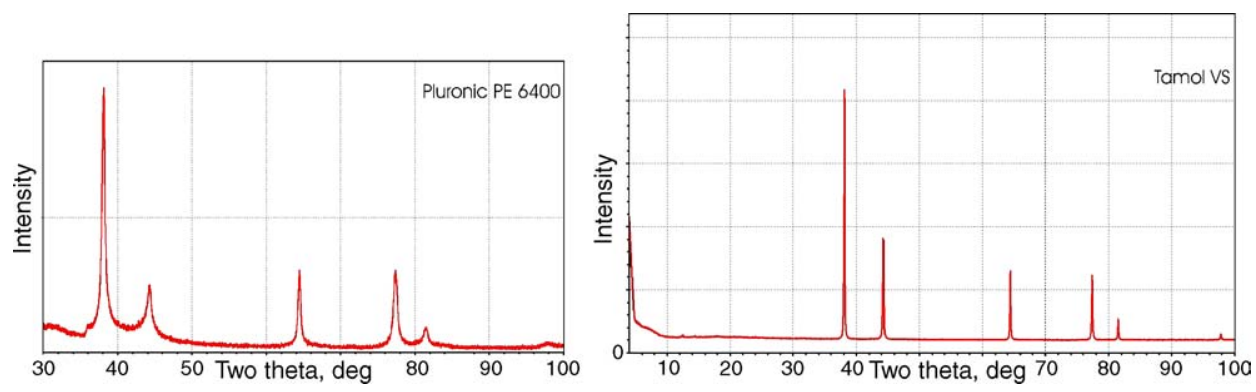

Fig. 1. X-ray patterns characteristic for a cubic system of crystalline metallic silver exhibit diversity in peak intensity and width.

that the silver particles consisted of. The sizes of the primary particles were determinated using the Scherrer formula. With addition of Pluronic, Plurafac LF, Gummi Arabicum or without a stabilizing agent, the primary particles are smaller than $10 \mathrm{~nm}$ in diameter. The $2 \Theta$ values of the Bragg-peaks were in all patterns characteristic for a cubic system of crystalline metallic silver $(F m \overline{3} m)$. Water and polymer content of the silver particles was determined thermogravimetrically. The TG curves indicated a weight loss between 1 and $4 \%$ attributed to water and polymer in the particles or on their surface. The chemical elemental analysis supported the thermogravimetric results and showed only a very low content of carbon (smaller than $0.36 \%$ ) as well as hydrogen (smaller than $0.10 \%$ ) and no presence of nitrogen.

\subsection{Influence of precursors and protecting agent concentrations}

Various ratios of precursors - silver nitrate, reducing agent, stabilising agent and Millipore water - were tested in order to determine the ratios leading to monodispersity in size and shape of the silver particles.

The concentration of silver nitrate in the reaction solution was varied between 0.01 and $0.1 \mathrm{M}$. An equimolar amount of the reducing agent was added. The concentration of polymer or organic salt was also varied between 0.01 and $0.1 \mathrm{M}$. The optimum in this investigation was found to be $1 \mathrm{ml}$ of $0.2 \mathrm{M}$ aqueous silver nitrate solution, $0.2 \mathrm{~mol}$ reducing agent, $2 \mathrm{ml}$ of $0.1 \mathrm{M}$ polymer solution, and $8 \mathrm{ml}$ Millipore water. Variations of the concentrations show a significan effect on the uniformity in morphology of the particles. Additionally, a decrease of average particle sizes with an increase of silver nitrate concentration was found. Similar tendencies were observed for the concentrations of reducing and stabilising agents, i.e. with higher concentra- tions of the reactants we obtained smaller particle sizes. In the series of Plurafac LF polymers, from LF 221 to LF 1300, smaller particles with higher molecular weight of the polymer were obtained. Higher molecular weight means higher fraction of polymer in the water solution, and can be compared with higher concentration of a stabilising agent in the solution.

\subsection{Influence of the type of reducing and stabilising agent}

The size and shape of the silver particles could be controlled by the addition of various polymer molecules and organic salts (Table 1). Depending on the type of stabilising agent, the particles prepared with ascorbic acid as reductant were up to $6 \mu \mathrm{m}$ in diameter. The average particle sizes were in the range from 3 to $4 \mu \mathrm{m}$. These particles consisted of smaller particles shown on the scanning electron micrograph in Fig. 2; left.

The reason for the various particle morphologies was the diversity of the interactions between the polar groups of the stabilising agents and the silver. Nitrogen and oxygen atoms of polar groups like imides in PVP (polyvinylpyrrolidon), the ether groups in Pluronic PE (PEO-PPO-PEO-block copolymer) and Plurafac LF or hydroxyl groups in Gummi Arabicum (polysaccharide) had a strong affinit to silver ions and metallic silver. However, the interactions between the ether or hydroxyl groups were not as strong as these with imines in PVP. For this reason the particles synthesised without an addition of a stabilising agent were similar to the results obtained with Pluronic PE, Plurafac LF or Gummi Arabicum. The particles had a morphology best described as a rice ball. They were up to $4 \mu \mathrm{m}$ in diameter and consisted of rods with a length of 300-600 nm (Fig. 2,1). In contrast, with PVP as protecting agent, we obtained plates with sizes up to $3 \mu \mathrm{m}$ and particles with sizes between 300 and $500 \mathrm{~nm}$ in diameter (Fig. 2; right).
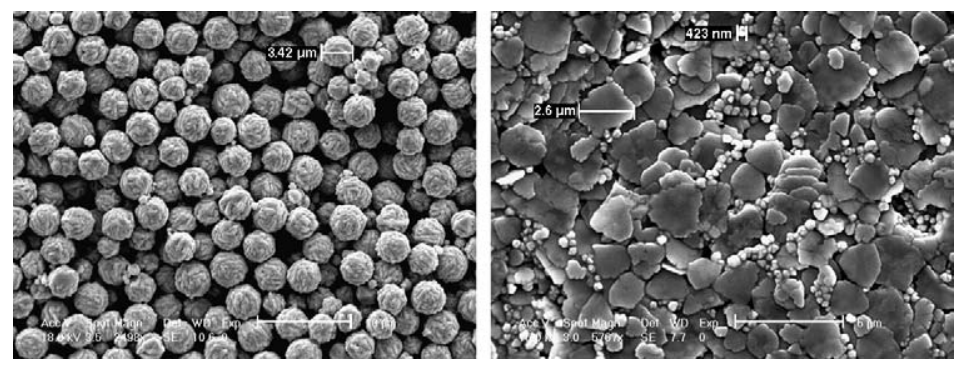

Fig. 2. Silver particles synthesised with addition of Plurafac LF 221 as stabilising agent (left) and with addition of PVP as stabilising agent (right). Ascorbic acid was used as reductive agent. 


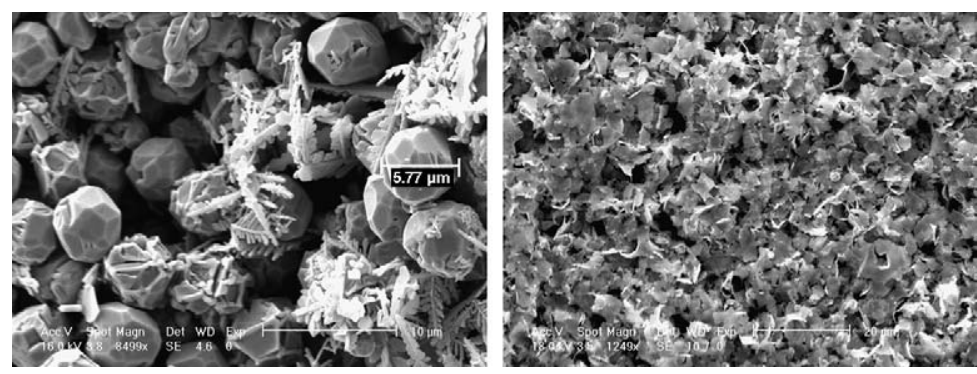

Fig. 3. Silver particles synthesised with addition of Tamol VS as stabilising agent and with addition of Lutensit A, ES as stabilising agent. Ascorbic acid was used as reductive agent.

The particles obtained with Tamol VS and Emulphor FAS 30 looked like polyhedrals or leafs. They have no similarity with the morphology of other particles (Fig. 3; left). Tamol VS and Emulphor FAS 30 are both sodium salts of an organic compound, and consequently their polar groups showed another type and strength of interaction with the silver ions and metallic silver than the pure organic polar groups. The polymer molecules of Lutensit A-ES have polar functional groups like ether and hydroxyl groups, additionally this polymer is an anionic tenside with sulfate as anion and sodium as cation. The very strong interaction between the organic polar groups or the ions and silver resulted in very thin and large plates as particles shape (Fig. 3; right).

The addition of alkali halogenide salts to the reaction solution yielded particles, which were morphologically not uniform and showed a very broad size distribution, independent of the used alkali halogenide salt.

The size of the particles depended strongly on the type of reductant (Table 2). Only with ascorbic acid as reductant the variety of curious shapes described above were obtained. Silver particles prepared with hydroquinone as reducing agent ranged from 500 to $1000 \mathrm{~nm}$ in size and exhibited irregular shapes independent of the added polymer molecules. Those synthesised with sodium borohydride were in the range from 300 to $600 \mathrm{~nm}$ and also showed irregular shapes. Further investigations showed, that the use of iron ammonium citrate yielded very small particles in sizes under $50 \mathrm{~nm}$ in diameter. Cölfen and Antonietti [9] established that the reductants in the system have different potentials to inhibit the growth of silver particles. The best growth inhibitor in this case was iron ammonium citrate and yielded particles on nanometer scale. The carboxyl and hydroxyl groups of citrate, the nitrogen atom of ammonia and the iron ion make strong interactions between the reductant and the silver ions possible and prevent further agglomeration, the particles remain very small.

Table 2

Reductive agents and resulting particle sizes

\begin{tabular}{ll}
\hline Reductive agent & Particle size \\
\hline Ascorbic acid & Up to $6 \mu \mathrm{m}$ \\
Hydroquinone & $500-1000 \mathrm{~nm}$ \\
Sodium borohydride & $300-600 \mathrm{~nm}$ \\
Iron ammonium citrate & $<50 \mathrm{~nm}$ \\
\hline
\end{tabular}

In addition to the interactions between the stabilising and reducing agent and the silver, there are also interactions between the agents themselves. Furthermore, some of the added polymer molecules, for instance PVP, also act reductively and support the activity of reducing agents [2].

\subsection{UV/VIS spectroscopy}

Due to the potential of silver particles for photonic applications (SERS, photonic crystals) the optical properties of the particles were investigated by extinction measurement (UV/VIS). The physical origin of the extinction in this wavelength range lies in the coherent oscillation of conduction band electrons induced by the electromagnetic field the so-called surface plasmon resonance. Mie scattering represents the major part of the extinction. The exact shape of the curves, is sensitive to particle size, shape, and polydispersity. Also, the dielectric constant (i.e. the kind of metal) and the solvent play a important role. We studied diluted suspensions of silver particles with different shapes and radii in the range from 200 to $1000 \mathrm{~nm}$ (Fig. 4). The spectra of large and non-uniform particles showed an extinction band with a maximum at about $300 \mathrm{~nm}$ and a broad extinction band starting after a sharp minimum at $320 \mathrm{~nm}$. Spherical, monodisperse and small (sizes below $20 \mathrm{~nm}$ in diameter) particles should only show one

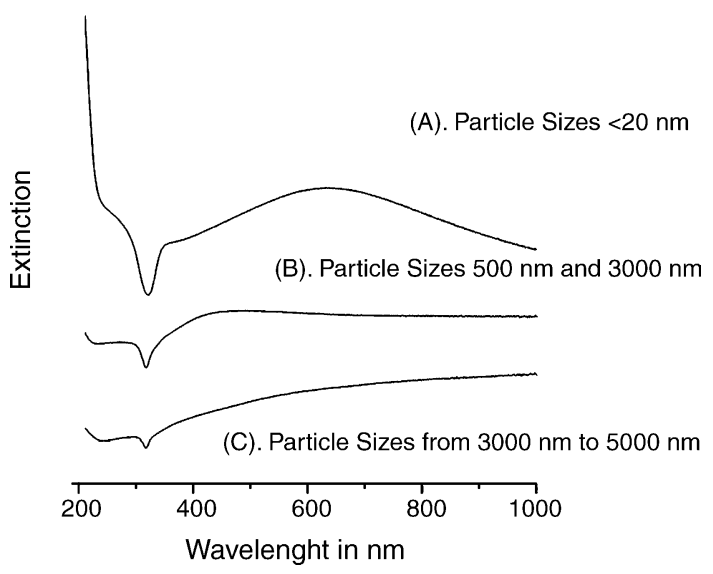

Fig. 4. UV/VIS measurements of silver particles: (a) silver particles with sizes, $<20 \mathrm{~nm}$, synthesised with iron ammonium citrate as reductant; (b) silver particles with 500 and $3000 \mathrm{~nm}$ in diameter, synthesised with ascorbic acide as reductant and PVP K 25 as stabilising agent; and (c) silver particles with sizes in the range from 3000 to $5000 \mathrm{~nm}$ in diameter, synthesised with ascorbic acide as reductant and Tamol VS as stabilising agent. 


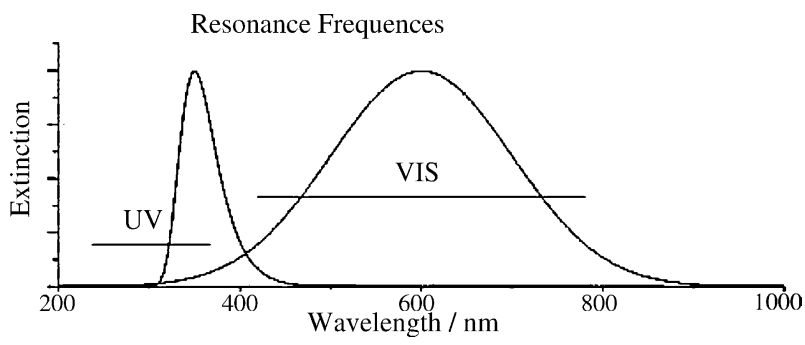

Fig. 5. Model of an UV/VIS spectrum with two extinction bands for two different polarisation directions of the two components of the electric field Parallel to the short axis of the particles the resonance frequency is higher than parallel to the longer axis of the particles.

extinction band at short wavelengths. Elongated or polydisperse particles, like our silver particles, exhibit two bands. The greater the particle elongation, the greater the separation of these two modes [12], The presence of two bands could be explained by two different polarisation directions. For the component of the electric field which is parallel to the short axis of the particles the resonance frequency is higher than for the component, parallel to the longer axis of the particles (Fig. 5) [13]. All obtained curves displayed a sharp minimum at $320 \mathrm{~nm}$. The depth of this minimum depended on the particle radius. However, the position is determined by the dielectric properties of the metal [3]. A deep minimum was observed for particles synthesised with PVP (Fig. 2; right). The measured sample consisted of particles of about $500 \mathrm{~nm}$ in diameter and thin plates, which were up to $3000 \mathrm{~nm}$ in size. A shallower minimum was obtained for particles prepared with Tamol VS with sizes from 3000 to $5000 \mathrm{~nm}$ (Fig. 3; left). The extinction band at longer wavelength is not dying out until $1000 \mathrm{~nm}$ for these samples. The deepest minimum was obtained for the silver nanoparticles with sizes under $20 \mathrm{~nm}$. In this case the longer wavelength band ended at about $1000 \mathrm{~nm}$ due to smaller particle sizes and weaker interactions between nanoparticles, compared to samples synthesised with PVP or Tamol VS.

In the literature there are at least two explanations proposed for the appearance of the broad extinction band at longer wavelength. Some authors have attributed it to the presence of a second distribution of larger, elongated or polydisperse particles [14]. Others have suggested that it arises from light extinction due to higher order surface plasmon modi the resulted inter alia from interactions of nanoparticles $[15,16]$. Heard et al. also postulated that its origin could be explained by assuming the presence of aggregates of primary particles interacting collectively with the incident light as a large silver particle [7,8,17]. Given that our particles were large and elongated and consisted of smaller interacting primary particles, we can accept all these explanations for our curves. The smaller particles show weaker interactions with each other and for this reason a less broader band at the longer wavelengths.

\section{Conclusion}

Our investigations of the synthesis of silver particles demonstrate that the interaction between the reducing or stabilising agent and metallic silver strongly affects the size and shape of the particles. Various morphologies and sizes of silver particles could be obtained in dependence of the additional reactants. Powder X-ray diffraction exhibited patterns with different peak intensities and width. They indicated, that some of the fina particles consisted of aggregated nanoparticles with sizes under $10 \mathrm{~nm}$ in diameter. All of them, however, were characteristic for a cubic system of crystalline metallic silver. Size and shape of these nanoparticles probably influenc the morphology of the fina particles. Thermogravimetry and elemental analysis showed that the added polymer molecules or organic salts were only at the surface of silver particles and were not built into the particles.

\section{Acknowledgements}

We thank F. Mengens for the UV/VIS measurements and Dr. G. Kollmannsberger-von Nell for helpful discussions (Group of Prof. Dr. E. Daltrozzo). We are grateful for access to characterisation techniques in the groups of Prof. Felsche, Prof. Scheer and Prof. Rathmayer. This work was performed with financia support from the Deutsche Forschungsgemeinschaft (SPP 1113, EI 488/2/1, University of Konstanz).

\section{References}

[1] W.C. Bell, M.L. Myrick, J. Colloid Interface Sci. 242 (2001) 300.

[2] P.-Y. Silvert, R. Herrera-Urbina, N. Duvauchelle, V. Vijayakrishnan, K.T. Elhisissen, J. Mater. Chem. 6 (1996) 573.

[3] K.P. Velikov, G.E. Zegers, A van Blaaderen, Langmuir 19 (2003) 1384.

[4] M. Yamamoto, M. Nakamoto, J. Mater. Chem. 13 (2003) 2064.

[5] I. Sondi, D. Goia, E. Matijevic, J. Colloid Interface Sci. 260 (2003) 75 .

[6] S. Eiden-Assmann, J. Widoniak, G. Maret, Chem. Mater. 16 (2004) 6.

[7] C. Xia, Y. Sun, Science 298 (2002) 2176.

[8] C. Xia, Y. Sun, Adv. Mater. 15 (2003) 695.

[9] H. Cölfen, M. Antonietti, Langmuir 14 (1998) 582.

[10] C. Göltner, H. Cölfen, M. Antonietti, Chem. unserer Zeit 33 (1999) 200.

[11] J.D. Hopwood, S. Mann, Chem. Mater. 9 (1997) 1819.

[12] C.F. Bohren, D.R. Huffman, Wiley Science Paperback Series, 1998.

[13] A. Volke, G. Heine, Photonik 3 (2004) 70.

[14] R. He, X. Qian, J. Yin, Z. Zhu, J. Mater. Chem. 12 (2002) 3783.

[15] A. Henglein, J. Phys. Chem. 97 (1993) 5457.

[16] A. Henglein, Chem. Mater. 10 (1998) 444.

[17] S.M. Heard, F. Grieser, C.G. Barraclough, J. Colloid Interface Sci. 93 (1983) 545 . 